\title{
Protein Kinase C-Mediated Inhibition of $\mu$-Opioid Receptor Internalization and Its Involvement in the Development of Acute Tolerance to Peripheral $\mu$-Agonist Analgesia
}

\author{
Hiroshi Ueda, Makoto Inoue, and Takayuki Matsumoto \\ Department of Molecular Pharmacology and Neuroscience, Nagasaki University School of Pharmaceutical Sciences, \\ Nagasaki 852-8521, Japan
}

\begin{abstract}
We investigated the role of protein kinase $C$ (PKC) in cell $\mu$-opioid receptor (MOR) internalization and MOR-mediated acute tolerance in vivo. When Chinese hamster ovary cells expressing MOR were exposed to [D-Ala ${ }^{2}, \mathrm{MePhe}^{4}, \mathrm{Gly}^{-o l^{5}}{ }^{5}-$ enkephalin (DAMGO), receptor internalization was observed at 30 min. Incubation with morphine failed to induce receptor internalization. When calphostin C, a PKC inhibitor, was added, receptor internalization was observed as early as 10 min after morphine stimulation. The MOR internalization induced by DAMGO or morphine in the presence of calphostin $C$ was dynamin dependent, because it was abolished $2 \mathrm{~d}$ after pretreatment with recombinant adenovirus to express a dominant interfering dynamin mutant (K44A/dynamin adenovirus). On the other hand, in a peripheral nociception test in mice, the noci-
\end{abstract}

ceptive flexor response after intraplantar injection (i.pl.) of bradykinin was markedly inhibited by DAMGO (i.pl.). DAMGO analgesia was not affected by $2 \mathrm{hr}$ prior injection (i.pl.) of DAMGO. Marked acute tolerance was observed after pretreatment with dynamin antisense oligodeoxynucleotide or K44A/dynamin adenovirus. The DAMGO-induced acute tolerance under such pretreatments was inhibited by calphostin C. Together, these findings suggest that PKC desensitizes MOR or has a role in the development of acute tolerance through MOR by inhibiting internalization mechanisms as a resensitization process.

Key words: protein kinase C; peripheral acute tolerance; internalization; $\mu$-opioid receptor; dynamin; K44A/dynamin adenovirus
Prolonged and repeated exposure to opioid agonists reduces the responsiveness of G-protein-coupled opioid receptors. This reduction in receptor function is hypothesized to contribute to opioid tolerance, dependence, and addiction in humans (Nestler, 1992). Substantial experimental evidence has divided this reduced function into separate but correlated receptor events: (1) desensitization, (2) internalization, and (3) downregulation (for review, see Bunemann and Hosey, 1999; Law et al., 2000). The molecular event underlying opioid tolerance in vitro is receptor desensitization. According to current understanding, opioid receptors are desensitized on the cell surface through a phosphorylation process in the C terminal (Pak et al., 1997; Afify et al., 1998) and/or third intracellular loop (Koch et al., 1997). On the other hand, receptor internalization, or receptor disappearance from the cell surface, is now believed to contribute to resensitization through dephosphorylation during endosomal stages (Krueger et al., 1997; Zhang et al., 1997). Downregulation is a loss of receptor protein in cells through increased degradation or decreased synthesis of the receptor. Little is known, however, regarding the regulation of this mechanism and involvement in opioid tolerance. Thus, much research has focused on the molec-

\footnotetext{
Received Jan. 23, 2001; revised Feb. 9, 2001; accepted Feb. 13, 2001.

Parts of this study were supported by Special Coordination Funds of the Science and Technology Agency of the Japanese Government and Human Frontier Science Program. We thank Dr. V. Höllt for the kind gift of MOR1 antiserum, Dr. H. Takeshima for the kind gift of CHO cells stably expressing rat MOR, and Dr. J. E. Pessin for the kind gift of Lac Z and K44A/dynamin adenovirus. We also thank I. Shimohira and T. Yamada for technical help.

Correspondence should be addressed to Dr. Hiroshi Ueda, Department of Molecular Pharmacology and Neuroscience, Nagasaki University School of Pharmaceutical Sciences, 1-14 Bunkyo-machi, Nagasaki 852-8521, Japan. E-mail: ueda@net.nagasaki-u.ac.jp.

Copyright (c) 2001 Society for Neuroscience $\quad 0270-6474 / 01 / 212967-07 \$ 15.00 / 0$
}

ular basis of events in receptor phosphorylation in the membranes and internalization. Recent studies revealed that cAMPdependent protein kinase (PKA) (Harada et al., 1990), protein kinase C (PKC) (Gucker and Bidlack, 1992; Ueda et al., 1995; L. Zhang et al., 1996), $\mathrm{Ca}^{2+} /$ calmodulin-dependent protein kinases (Koch et al., 1997), G-protein-coupled receptor kinases (GRKs) (Pei et al., 1995; Zhang et al., 1998), and mitogenactivated protein kinase (Polakiewicz et al., 1998) have roles in opioid receptor phosphorylation. PKC and GRK mechanisms are likely candidates for opioid desensitization and internalization (L. Zhang et al., 1996; Zhang et al., 1998).

Our goal is to clarify the molecular events in opioid tolerance through studies on the regulation of receptor internalization. We previously reported in vivo desensitization or tolerance to morphine analgesia through PKC mechanisms using peripheral nociception tests in mice (Inoue and Ueda, 2000). Because complex neuronal networks in the CNS are not likely to be involved in the peripheral nociceptive test model used, the site of morphine action, including analgesia and acute tolerance, can only be in nociceptor endings (Inoue and Ueda, 2000). The next strategy to study the relationship between opioid receptor internalization and opioid acute tolerance was initiated by attempts to clarify the mechanism of distinct behaviors of receptor internalization after stimulation with different agonists. [D-Ala ${ }^{2}, \mathrm{MePhe}^{4}, \mathrm{Gly}_{-} \mathrm{ol}^{5}$ ]enkephalin (DAMGO), a peptide $\mu$-opioid receptor (MOR) agonist, effectively induced the internalization of MOR expressed in mammalian cells, whereas morphine did not (Whistler et al., 1999). The present study reports the involvement of PKC in the inhibition of MOR internalization and development of acute $\mu$-opioid tolerance, with an analysis of distinct mechanisms using morphine or DAMGO. 


\section{MATERIALS AND METHODS}

Animals. Male ddY-strain mice weighing 20-22 gm were maintained at $21 \pm 2{ }^{\circ} \mathrm{C}$ with ad libitum access to a standard laboratory diet (MF; Oriental Yeast, Tokyo, Japan) and tap water. Procedures were approved by the Nagasaki University Animal Care Committee and were in accordance with the recommendations of the International Association for the Study of Pain (Zimmermann, 1983).

Drug treatments. Chinese hamster ovary (CHO) cells stably expressing rat MOR were a kind gift from Dr. Hiroshi Takeshima (Fukuda et al., 1993). Cells were maintained in minimum essential medium $\alpha$ ( $\alpha$ MEM; Life Technologies, Tokyo, Japan) supplemented with $10 \%$ fetal bovine serum, streptomycin $(100 \mu \mathrm{g} / \mathrm{ml})$, and penicillin $(100 \mathrm{U} / \mathrm{ml})$ in a humidified atmosphere of $95 \%$ air $/ 5 \% \mathrm{CO}_{2}$. The drugs used were morphine (Takeda Chemical Industries, Osaka, Japan), DAMGO, bradykinin (BK), KN93 (Sigma, St. Louis, MO), calphostin C and KT5720 (Kyowa Medics, Tokyo, Japan), and Go6976, 2,2',3,3',4,4'-hexahydroxy-1,1'biphenyl-6,6'-dimethanol dimethyl ether (HBDDE), and Rottlerin (Calbiochem, La Jolla, CA). Calphostin C, KT5720, Go6976, HBDDE, and Rottlerin were dissolved in $30 \%$ DMSO, and other drugs were dissolved in physiological saline or culture medium. In many experiments, drugs other than calphostin C and KT5720 were administered by intraplantar injection in a volume of $2 \mu \mathrm{l}$. Calphostin C and KT5720 were administered by intraplantar injection in a volume of $5 \mu$. The antisense oligodeoxynucleotide (AS-ODN) (5'-CCG CGG TTG CCC ATG GT-3') and its missense (MS-ODN) (5'-CCG GCG TTC GCC AGT GT-3') for mouse dynamin were synthesized, dissolved in physiological saline, and used for intrathecal (i.t.) injection according to the protocol of Hylden and Wilcox (1980) in a volume of $2 \mu \mathrm{l}$ on the first, third, and fifth day. On the sixth day, mice were assessed for opioid analgesia. The recombinant adenovirus to express a dominant interfering dynamin mutant (K44A/ dynamin adenovirus) and the LacZ-encoding adenovirus (LacZ adenovirus) for evaluation of analgesia on nociceptive flexor responses and for immunocytochemistry were a kind gift from Dr. J. E. Pessin (Kao et al., 1998). Amplification and titration of these adenoviruses were performed according to the method of Becker et al. (1994).

For animal experiments, the adenoviruses were freshly dissolved in physiological saline and used for injection in a volume of $5 \mu$ l (i.t.). On the third and fifth day, mice were assessed for analgesia. For the immunocytochemical experiments, cells were infected with adenoviruses that were freshly dissolved in medium. After $2 \mathrm{~d}$, cells were treated with several drugs, and immunocytochemistry was performed. MOR1 antiserum for immunocytochemistry experiments was a kind gift from Dr. V. Höllt (Schulz et al., 1998).

MOR internalization using confocal laser microscopy. CHO cells stably expressing MOR1 were grown on poly-L-lysine-treated coverslips overnight. Cells were then exposed to $1 \mu \mathrm{M}$ DAMGO or $10 \mu \mathrm{M}$ morphine for $0,10,30$, or $60 \mathrm{~min}$. Cells were fixed with Zamboni's fixative $(4 \%$ paraformaldehyde and $0.2 \%$ picric acid in $0.1 \mathrm{M}$ phosphate buffer) for 45 min at room temperature and subsequently washed several times in PBS $(-)$. After $1 \mathrm{hr}$ of preincubation in PBS containing $0.3 \%$ Triton X-100 and 3\% normal goat serum, cells were incubated with anti-MOR1 antibody at a dilution of 1:5000 in PBS containing 0.3\% Triton X-100 and 1\% normal goat serum overnight at room temperature. Bound primary antibody was detected using cyanin 3(Cy3)-conjugated anti-rabbit IgG (1:200; Chemicon, Temecula, CA). Cells were then washed several times in PBS $(-)$, dehydrated, and permanently mounted in Aqua-Poly/Mount (Polyscience). Specimens were examined using a Fluoview laser scanning confocal microscope (Olympus). Cy3 was imaged with $568 \mathrm{~nm}$ excitation and a BA585IF filter. Confocal micrographs were taken by a person blinded to the treatments who was instructed to randomly select one colony of 4-12 cells per coverslip.

Immunocytochemistry of dorsal root ganglion. The reduction in dynamin expression in the dorsal root ganglion after intrathecal treatments with AS-ODN for dynamin was analyzed using immunocytochemistry. On the sixth day after repeated treatments with AS-ODN (or MS-ODN), mice were anesthetized with diethylether and perfused via the left ventricle with PBS followed by Zamboni's fixative at $4^{\circ} \mathrm{C}$. Dorsal root ganglia were then removed and cryoprotected in $25 \%$ sucrose in PBS overnight at $4^{\circ} \mathrm{C}$. Samples were quickly frozen in OCT compound (Sakura Finetechnical, Tokyo, Japan) on dry ice and stored at $-20^{\circ} \mathrm{C}$. All of the following procedures were performed at room temperature. Sections of $6 \mu \mathrm{m}$ thickness on gelatin-coated glass slides were incubated with blocking solution (3\% normal goat serum and $0.3 \%$ Triton X-100/PBS) for $60 \mathrm{~min}$. The sample was then incubated with biotinylated monoclonal mouse anti-dynamin IgG1 (Transduction Laboratories, Lexington, KY;

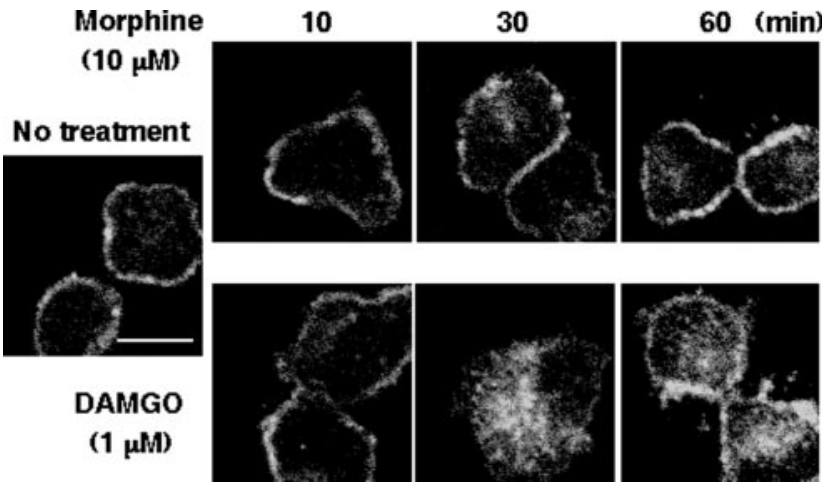

Figure 1. Comparison of agonist-induced internalization of MOR in CHO cells. MOR1-expressing CHO cells were exposed to $10 \mu \mathrm{M}$ morphine or $1 \mu \mathrm{M}$ DAMGO for the indicated time periods at $37^{\circ} \mathrm{C}$. After fixation, the cells were stained with anti-MOR1, followed by Cy3conjugated anti-rabbit IgG, and examined by confocal laser microscopy. Representative results are shown. Scale bar, $10 \mu \mathrm{m}$.

$1: 100,2.5 \mu \mathrm{g} / \mathrm{ml}$ ) diluted in $1 \%$ normal goat serum/PBS for $90 \mathrm{~min}$. After washing with PBS three times for 5 min, the sample was incubated with Texas red-streptavidin (Amersham, Tokyo, Japan; 1:100) for $1 \mathrm{hr}$, washed with PBS three times for 5 min, and mounted with glycerol/PBS.

Evaluation of analgesia on nociceptive flexor responses. Experiments were performed as described previously (Inoue et al., 1998a,b; Ueda, 1999). Briefly, mice were lightly anesthetized with ether and held in a cloth sling with all four limbs hanging free through holes. The sling was suspended on a metal bar. The limbs were tied with strings, and three limbs were fixed to the floor, whereas the other one was connected to an isotonic transducer and recorder. Two polyethylene cannulas (outer diameter, $0.61 \mathrm{~mm}$ ) filled with drug solution were connected to separate microsyringes. One cannula was filled with BK or saline, and the other was filled with test drugs. All experiments were started after complete recovery of the mouse from the light ether anesthesia (20-30 min) and confirmation that the intraplantar injection of saline did not induce any significant flexor responses. BK was given intraplantarly at 10 and $5 \mathrm{~min}$ before and 5, 10, 20, and $30 \mathrm{~min}$ after opioid or vehicle injection. In most experiments, the results were expressed as percentage analgesia, using the following equation: $[1-\mathrm{BK}$ response $(\mathrm{mm})$ after test drug administration/the average of two control BK responses] $\times 100(\%)$. In some experiments, analgesia was also evaluated by the area under the curve (AUC) obtained by plotting analgesia $(\%)$ on the ordinate and time after DAMGO (i.pl.) administration (min) on the abscissa. In this case, DAMGO analgesia was assessed by percentage of the maximal AUC, which represents the analgesia when the BK response is completely inhibited during periods from 5 to $30 \mathrm{~min}$ after drug injection. Thus, the maximal AUC was calculated to be $2500(\% \times$ min $)$. The SEM was determined from four to six experiments, in which three different doses of DAMGO were tested. Opioid agonists were given through another cannula 5 min after the second control BK response, whereas PKC inhibitors were given $5 \mathrm{~min}$ before the challenge of opioid agonists. All animals were used for only one experiment by an observer who did not know which pretreatments had been given.

Statistical analysis. In the experiment using different time periods, statistical evaluations were performed using the Dunnett test for multiple comparisons after one-way ANOVA. Statistical evaluations were performed using the Student's $t$ test, after one-way ANOVA in the experiment using AS-ODN or adenovirus. In the experiment evaluating the effects of the PKC inhibitor on DAMGO-induced acute tolerance, statistical evaluations were performed using the Scheffe test for multiple comparisons after one-way ANOVA. Data were expressed as mean \pm SEM. A $p$ value of $<0.05$ was considered significant.

\section{RESULTS}

\section{Distinct MOR internalization after stimulation with different agonists}

MOR1-like immunoreactivity (MOR-Li) was detected mostly at the level of the plasma membrane of CHO cells stably expressing MOR1 using confocal laser microscopy (Fig. 1). When cells were 


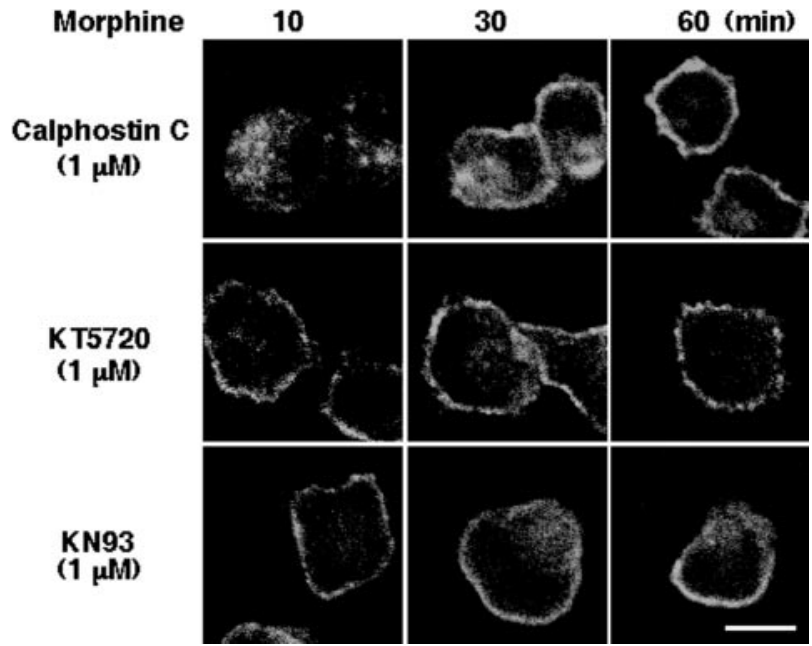

Figure 2. Morphine-induced MOR-Li internalization in the presence of various protein kinase inhibitors. $\mathrm{CHO}$ cells expressing MOR1 were exposed to $10 \mu \mathrm{M}$ morphine for the indicated time periods in the presence of $1 \mu \mathrm{M}$ calphostin $\mathrm{C}$, KT5720, or $\mathrm{KN} 93$ at $37^{\circ} \mathrm{C}$. Other details are given in the legend for Figure 1.

incubated with $10 \mu \mathrm{M}$ morphine at $37^{\circ} \mathrm{C}$ for various time periods, there was no significant internalization of MOR-Li within $60 \mathrm{~min}$. On the other hand, there was marked internalization when cells were incubated with $1 \mu \mathrm{M}$ DAMGO for $30 \mathrm{~min}$, with partial recovery at $60 \mathrm{~min}$. Internalized MOR-Li was observed in vesiclelike structures within the cytoplasm, whereas MOR-Li in the plasmalemma disappeared completely. Such distinct differences in receptor dynamics between cells stimulated with morphine and DAMGO are consistent with previous studies using different cells (Keith et al., 1996, 1998; Sternini et al., 1996).

\section{Morphine-induced MOR internalization in the presence of a PKC inhibitor}

PKC mechanisms mediate opioid receptor desensitization and opioid analgesic tolerance (Narita et al., 1995; Ueda et al., 1995; Kramer and Simon, 1999). To relate PKC mechanisms to MOR internalization, $1 \mu \mathrm{M}$ calphostin $\mathrm{C}$, a representative $\mathrm{PKC}$ inhibitor, was added to the cell $10 \mathrm{~min}$ before morphine incubation. Marked MOR-Li internalization was observed 10 min after morphine was added. Recovery occurred at 30-60 min. Internalized MOR-Li was also observed in vesicle-like structures within the cytoplasm as in the case of DAMGO, and there was complete loss of the activity in the plasmalemma (Fig. 2, top panel). The treatment with vehicle (1\% DMSO) used for dissolving calphostin $\mathrm{C}$ had no effect on receptor internalization (data not shown).

Similar treatments with $1 \mu \mathrm{M} \mathrm{KT5720} \mathrm{or} \mathrm{KN93,} \mathrm{representative}$ inhibitors of PKA or calcium/calmodulin-dependent protein kinase II, respectively (Kase et al., 1987; Sumi et al., 1991), did not affect the dynamics of MOR1 internalization (Fig. 2). In addition, the calphostin $\mathrm{C}$ treatment did not affect the DAMGO-induced MOR-Li internalization (data not shown).

\section{Morphine-induced MOR internalization in the presence of a PKC isoform-specific inhibitor}

When $1 \mu \mathrm{M}$ Go6976, a specific inhibitor of the PKC $\alpha$ and $\gamma$ isoforms (Wenzel-Seifert et al., 1994), or $1 \mu \mathrm{M}$ HBDDE, a specific inhibitor of the PKC $\alpha$ and $\beta$ isoforms (Kashiwada et al., 1994), was added to the cell $10 \mathrm{~min}$ before morphine incubation, there was marked MOR-Li internalization at $10 \mathrm{~min}$ after the morphine challenge, as shown in Figure 3. As with calphostin $\mathrm{C}$, the

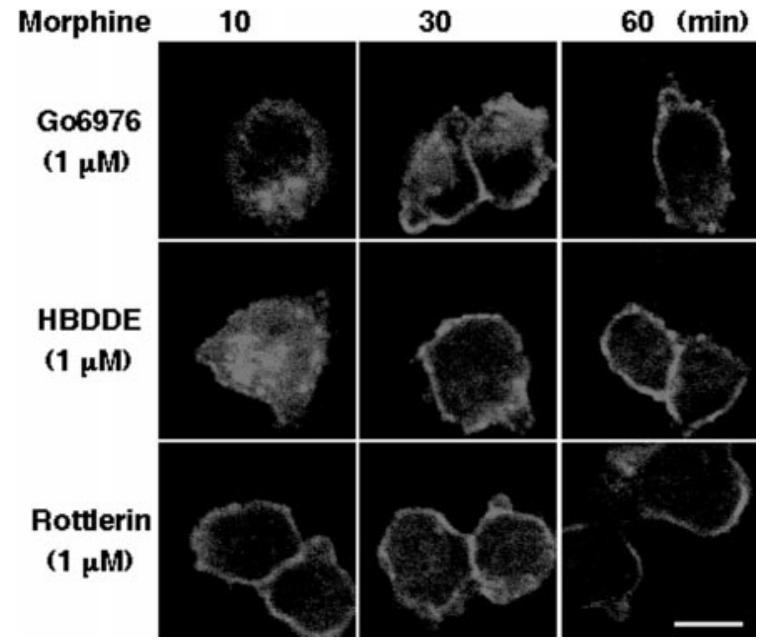

Figure 3. Morphine-induced MOR-Li internalization in the presence of a PKC isoform-specific inhibitor. CHO cells expressing MOR1 were exposed to $10 \mu \mathrm{M}$ morphine in the presence of various PKC inhibitors (1 $\mu \mathrm{M})$ for the indicated time periods at $37^{\circ} \mathrm{C}$. Other details are given in the legend for Figure 1.

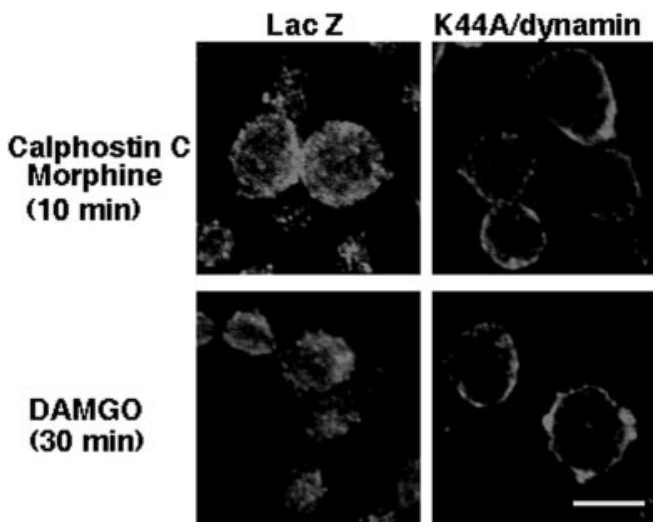

Figure 4. Dynamin-dependent MOR1 internalization. CHO cells expressing MOR1 were infected with Lac Z or K44A/dynamin adenovirus. After $2 \mathrm{~d}$, cells were exposed to $10 \mu \mathrm{M}$ morphine in the presence of $1 \mu \mathrm{M}$ calphostin $\mathrm{C}$ or $1 \mu \mathrm{M}$ DAMGO alone for the indicated time periods at $37^{\circ} \mathrm{C}$. Other details are given in the legend for Figure 1.

recovery of MOR-Li internalization was observed at $30 \mathrm{~min}$. On the other hand, $1 \mu \mathrm{M}$ Rottlerin, a specific inhibitor of the PKC $\delta$ isoform (Lu et al., 1997), did not induce any significant internalization.

\section{Dynamin-dependent MOR internalization}

The cells expressing MOR1 were infected with $1 \times 10^{-9} \mathrm{pfu} / \mathrm{ml}$ of the K44A/dynamin adenovirus and LacZ adenovirus $2 \mathrm{~d}$ before the experiments for MOR-Li internalization. As shown in Figure 4, morphine $(10 \mu \mathrm{M})$-induced internalization in the presence of calphostin $\mathrm{C}$ was not affected by infection with the negative control adenovirus containing the LacZ gene, whereas it was markedly inhibited by infection with the K44A/dynamin adenovirus. Infection with the K44A/dynamin adenovirus also blocked DAMGO (1 $\mu \mathrm{M})$-induced receptor internalization (Fig. 4).

\section{Lack of acute tolerance to DAMGO-induced peripheral analgesia}

As reported previously (Inoue and Ueda, 2000), infusion of BK $(2 \mathrm{pmol} / 2 \mu \mathrm{l})$ to the hindpaw planta elicited nociceptive flexor 

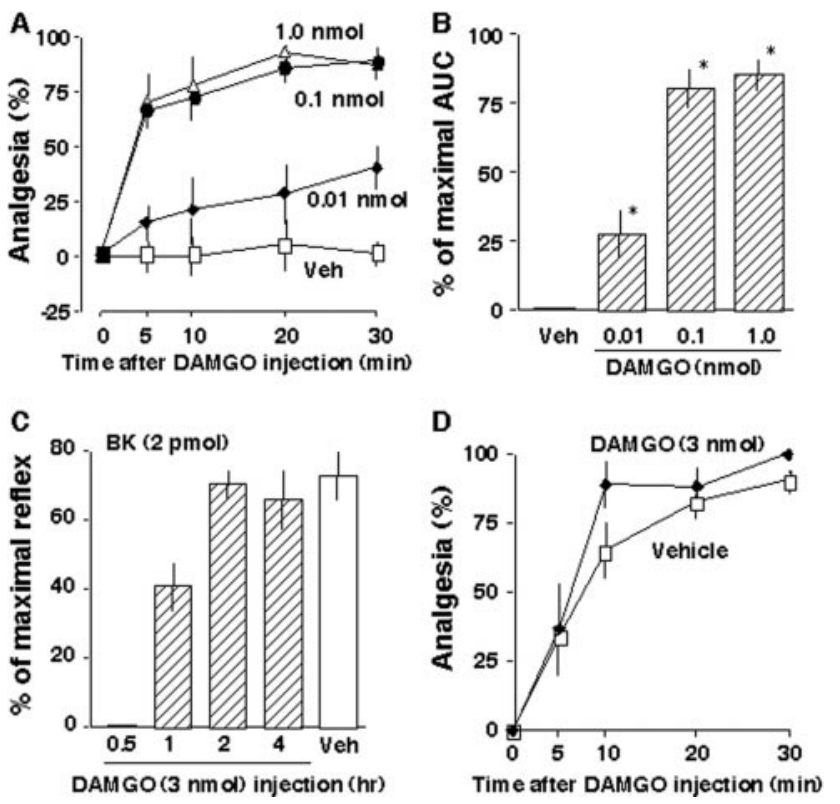

Figure 5. Lack of tolerance of DAMGO-induced peripheral analgesia. $A$, Time course of DAMGO analgesia. The results are expressed as analgesia $(\%)$. The analgesia was expressed as the decreasing ratio $(\%)$ of the described length of BK responses after DAMGO injection against the average of the described length of the second BK response before DAMGO injection. Each point shows the data with DAMGO $(\triangle, 1.0$ $\mathrm{nmol} ; \bullet, 0.1 \mathrm{nmol} ; \diamond, 0.01 \mathrm{nmol})$ or vehicle $(V e h, \square)$. B, Dose-dependent DAMGO-induced analgesia. The results are expressed as percentage of maximal AUC, as described in Materials and Methods. Data represent the mean \pm SEM from five separate experiments. ${ }^{*} p<0.05$, compared with vehicle-treated group. $C$, Time-dependent recovery of BK-induced nociceptive flexor responses after the first DAMGO administration. The BK (2 pmol)-induced nociceptive activity is represented by the percentage of maximal reflex observed before drug challenges at the beginning of each experiment. $D$, Lack of DAMGO-induced analgesic tolerance. Peripheral analgesic tests using BK and DAMGO were performed $2 \mathrm{hr}$ after the administration with DAMGO or vehicle. All data represent the mean \pm SEM from six separate experiments.

responses in mice, and the responses were constant for 30-60 min during repeated challenges of $\mathrm{BK}$ at 5 min intervals. The inf usion of DAMGO through another cannula markedly inhibited BKinduced flexor responses. Percentage analgesia was plotted against the time after DAMGO infusion (Fig. $5 A$ ). When the AUC (Fig. 5A) was evaluated, there appeared to be a dosedependent peripheral DAMGO-induced analgesia (Fig. $5 B$ ), because there was no significant analgesia when DAMGO was inf used to the other side in which BK was not administered (data not shown). The approximate $\mathrm{AD}_{50}$ of peripheral DAMGO analgesia was 33 pmol, which was eight times lower than that (274 pmol) with morphine (Inoue and Ueda, 2000).

We reported previously that the intraplantar infusion of morphine ( 3 nmol; a maximal dose) completely inhibited the BK responses, and the responses completely recovered to control levels $4 \mathrm{hr}$ after treatment (Inoue and Ueda, 2000). The second morphine $(3 \mathrm{nmol})$ challenge significantly attenuated the inhibition of BK responses. We called this attenuation acute tolerance to peripheral morphine analgesia. To examine whether acute tolerance developed to DAMGO analgesia, mice were given 3 nmol of DAMGO (i.pl.), a dose three times higher than the maximal dose (1 nmol) for peripheral analgesia, an increase similar to that used to study acute tolerance with morphine (Inoue and Ueda, 2000). When the nociceptive response to BK (2

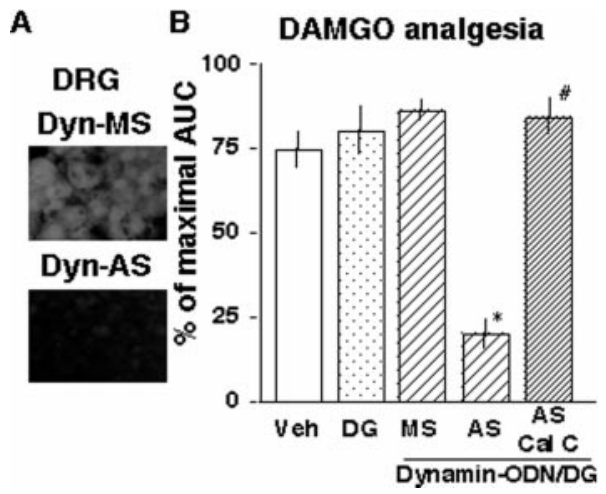

Figure 6. Calphostin C-sensitive DAMGO-induced analgesic tolerance in the dynamin AS-ODN-treated mice. Mice were given injections of AS-ODN (10 $\mu \mathrm{g} / 2 \mu$ l, i.t.) on the first, third, and fifth days. Immunocytochemistry using dorsal root ganglia and nociception test was performed on the sixth day. Details are given under Materials and Methods. $A$, The reduction of dynamin expression by treatment of AS-ODN for dynamin (Dyn- $A S)$, compared with the case with MS-ODN (Dyn-MS). B, Calphostin $\mathrm{C}$-sensitive DAMGO-induced analgesic tolerance. Peripheral nociception tests using BK and DAMGO were performed $2 \mathrm{hr}$ after coadministration with DAMGO $(3 \mathrm{nmol})$ and calphostin $\mathrm{C}(3 \mathrm{nmol})$. The results are expressed as percentage of maximal AUC, as described in Materials and Methods. All data represent the mean \pm SEM from four separate experiments. ${ }^{*} p<0.05$, when compared with the vehiclepretreated group. \# $p<0.05$, when compared with the AS-ODN-treated group.

pmol) was assessed at different times after the first DAMGO treatment, complete recovery was observed $2 \mathrm{hr}$ after the first DAMGO treatment (Fig. $5 C$ ). As shown in Figure 5D, DAMGO ( 3 nmol, i.pl.) infusion to mice pretreated with vehicle had a time course of analgesia similar to that of $1 \mathrm{nmol}$ of DAMGO in naive mice (Fig. 5A). There was no significant difference in the DAMGO-induced analgesia, however, between vehicle- and DAMGO-pretreated mice (Fig. 5D). Lack of DAMGO-induced analgesic tolerance was also observed when the second DAMGO injection was administered $4 \mathrm{hr}$ after the first challenge (data not shown).

\section{Acute tolerance to DAMGO analgesia induced by dynamin AS-ODN or K44A/dynamin adenovirus}

Thus, there is an inverse relationship between MOR1 internalization and acute tolerance. Morphine, which did not induce internalization, produced acute tolerance. On the other hand, DAMGO-induced internalization did not develop tolerance. Therefore the internalization likely prevents the acute tolerance or receptor desensitization. This view is consistent with current understanding that the internalization process is necessary for resensitization of desensitized receptors, possibly through dephosphorylation (Krueger et al., 1997). Here we attempted to determine the effects of the blockade of receptor internalization by dynamin AS-ODN on the lack of acute tolerance to DAMGO analgesia. Mice were treated with AS-ODN for dynamin 1, 3, and $5 \mathrm{~d}$ before the nociception test. On the sixth day after the first AS-ODN treatment, dorsal root ganglia were isolated and used for immunocytochemistry. The AS-ODN treatment markedly reduced the immunoreactive dynamin signal compared with MSODN treatment (Fig. 6A). The intrathecal treatments with dynamin AS-ODN did not affect the peripheral BK responses (data not shown), suggesting that spinal pain neurotransmission is not affected by such treatments. As shown in Figure $6 B$, however, marked acute tolerance to DAMGO analgesia was observed after 


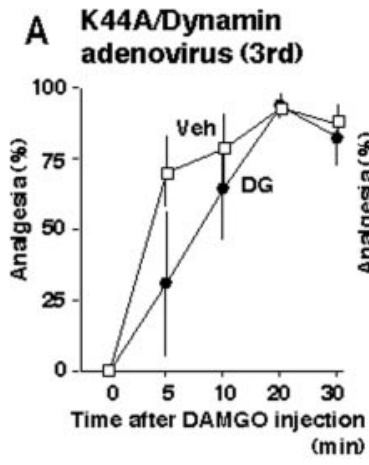

\section{B K44A/Dynamin} adenovirus (5th)

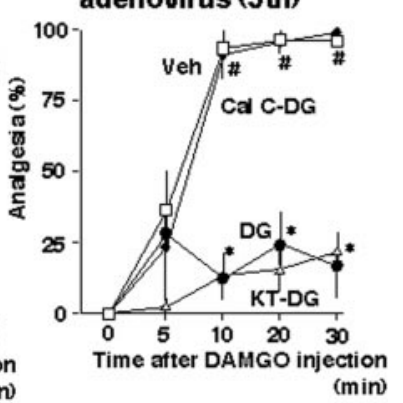

Figure 7. Calphostin C-sensitive acute tolerance to DAMGO analgesia in mice treated with $\mathrm{K} 44 \mathrm{~A}$ /dynamin adenovirus-treated mice. K44A/ dynamin adenovirus was injected in a volume of $5 \mu$ l (i.t.). On the third $(A)$ and fifth $(B)$ days, mice were assessed for opioid analgesia. The results are expressed as DAMGO $(D G ; 3 \mathrm{nmol}$, i.pl.)-induced analgesia $(\%)$ as described in Materials and Methods. Each point shows the data when mice were pretreated with $3 \mathrm{nmol}$ of DG (-), DG plus $3 \mathrm{nmol}$ of calphostin C (Cal C-DG, $\bullet$ ), DG plus $10 \mathrm{nmol}$ of KT5720 (KT-DG, $\triangle$ ), or vehicle $(V e h, \square)$. All data represent the mean \pm SEM from six separate experiments. ${ }^{*} p<0.05$, when compared with the vehicle-pretreated mice at each time point. $\# p<0.05$, when compared with the DG-pretreated mice at each time point. Other details are given in the legend for Figure 6.

the treatments with AS-ODN, but not with MS-ODN. Similar results were also observed after intrathecal treatment with K44A/ dynamin adenovirus (Fig. 7), which did not affect BK responses (data not shown). DAMGO analgesia on the second challenge was not affected on the third day after the adenovirus treatment (Fig. 7A), whereas complete loss of DAMGO analgesia was observed on the fifth day after treatment (Fig. 7B).

\section{PKC involvement in the acute tolerance of DAMGO- induced peripheral analgesia}

On the basis of the finding that PKC inhibitors blocked the acute tolerance to peripheral morphine analgesia (Inoue and Ueda, 2000), we examined the effects of calphostin $C$ treatment on the acute tolerance to DAMGO analgesia, because dynamin functions are expected to be inhibited by AS-ODN or adenovirus treatments. When calphostin C (3 nmol, i.pl.) was coadministered with DAMGO, the reduced analgesia on the second challenge of DAMGO under the AS-ODN treatment completely recovered to control levels (Fig. 6B). As shown in Figure $7 B$, there was a similar recovery of acute DAMGO tolerance under the adenovirus treatment when mice were treated with calphostin $\mathrm{C}(3 \mathrm{nmol})$, but not with KT-5720 (10 nmol).

\section{DISCUSSION}

The present study demonstrates two major findings on the role of MOR internalization in acute tolerance and modulation by PKC. Previous studies reported that MOR expressed in mammalian cells is internalized when stimulated by DAMGO but not morphine (Keith et al., 1996, 1998; Sternini et al., 1996). Preliminary findings indicated that endomorphin- 1 and -2 also induce marked internalization of MOR in the present system (our unpublished data), as reported elsewhere (Burford et al., 1998; McConalogue et al., 1999). The lack of internalization induced by morphine is not likely the result of morphine being an alkaloid, because etorphine and methadone also induce MOR internalization (Whistler et al., 1999). Recent studies using MOR mutagenesis revealed that the ligand binding site in the receptor is different between morphine and DAMGO (Onogi et al., 1995; Xu et al.,
1999). It remains to be fully determined, however, whether the different ligand binding sites between morphine and DAMGO underlie the discrepancy in MOR internalization.

Ligand-specific dependence of acute tolerance was also observed in the present study. We reported previously that morphine pretreatment markedly reduced peripheral morphine analgesia during a second challenge in the nociceptive test (Inoue and Ueda, 2000). DAMGO pretreatment did not show any change, however, in the present study. The inverse relationship between MOR internalization and acute tolerance after stimulation with two different agonists suggests that the internalization prevents acute tolerance or receptor desensitization. This view is consistent with current consensus on the role of internalization in the receptor desensitization mechanism (Krueger et al., 1997; J. Zhang et al., 1997; Bunemann and Hosey, 1999). It is further supported by the present in vivo findings that acute tolerance after DAMGO treatment was induced when mice were pretreated with dynamin AS-ODN. As mentioned above, this AS-ODN treatment does not likely affect spinal neurotransmission. Therefore, the alteration in DAMGO responses induced by AS-ODN might be caused by the reduced expression of dynamin in nociceptor endings, and these signaling mechanisms between MOR and dynamin might be at the level of nociceptor endings, corresponding to the mechanisms observed in cell lines. Similar results were also observed when K44A/dynamin adenovirus was added. The effects of intrathecal treatments with AS-ODN and adenovirus on spinal pain transmission might be attributed to poor permeability of ODN or adenovirus to the spinal cord through the pia matter, as reported previously (Iadarola et al., 1997; Ueda, 1999).

These findings suggest that MOR remaining in plasma membranes without being internalized are desensitized. Opioid receptor desensitization has long been discussed in relation to phosphorylation by several protein kinases. Desensitization of cloned $\delta$-opioid receptors by GRKs was first reported in experiments using GRK2 overexpression (Pei et al., 1995), and this finding is supported by other observations (Hasbi et al., 1998). In contrast, MOR is not desensitized or is very weakly desensitized by GRK2 overexpression, although there is significant phosphorylation of MOR (Kovoor et al., 1997; El Kouhen et al., 1999), suggesting the involvement of other mechanisms in MOR desensitization.

$\mathrm{PKC}$ is another protein kinase that might desensitize opioid receptors. The addition of calphostin $\mathrm{C}$, a PKC inhibitor, to the reaction mixture enhances $\delta$-opioid agonist-stimulated G-protein activation in guinea pig striatal membranes, COS cells, and Xenopus oocytes expressing the $\delta$-opioid receptor (Fukushima et al., 1994; Hayashi et al., 1995; Ueda et al., 1995). There are also several reports suggesting that PKC is involved in MOR desensitization using cell lines expressing MOR and in in vivo acute tolerance (for review, see Smart and Lambert, 1996). The present study focused on acute tolerance at the level of nociceptor endings, in which complicated neuronal networks could be excluded from the molecular mechanisms. This might be the case in the lack of acute tolerance to peripheral DAMGO analgesia. This contrasts with a previous report showing acute tolerance to central (i.t.) DAMGO analgesia, which was reversed by intrathecal calphostin C (Narita et al., 1995), suggesting that mechanisms involving neuronal networks underlie the central DAMGO analgesic tolerance. It should be noted that PKC inhibitors induced recovery of acute tolerance to peripheral morphine analgesia or peripheral DAMGO analgesia after treatments with AS-ODN or with K44A/dynamin adenovirus (Inoue and Ueda, 2000) (Figs. $6 B, 7)$. These findings strongly suggest that PKC desensitizes 
MOR and in turn induces acute tolerance to peripheral analgesia through MOR.

On the other hand, treatment with PKC inhibitors caused morphine-induced MOR internalization. This finding suggests that PKC actions prevent the MOR internalization and resensitization process through recycling. In the present study, the subclassification of PKC isoforms involved in such mechanisms (Way et al., 2000) was pharmacologically characterized. Go6976, an inhibitor of PKC $\alpha$ and $\gamma$, and HBDDE, an inhibitor of PKC $\alpha$ and $\beta$, but not Rottlerin, an inhibitor of PKC $\delta$, caused MOR internalization after morphine treatment. Therefore, conventional but not novel types of PKC might have a role in such desensitization mechanisms. It should be noted that DAMGOinduced MOR internalization was observed at $30 \mathrm{~min}$ after the agonist stimulation, whereas morphine-induced MOR internalization in the presence of calphostin C was observed as early as 10 min after the agonist stimulation. Because the addition of Go6976 and HBDDE also caused morphine-induced internalization at 10 min, the different kinetics for internalization between DAMGO and morphine are likely caused by the inhibition of PKC, but not to nonspecific actions.

Although the mechanism underlying such differences involving PKC mechanisms between morphine and DAMGO remains unclear, variations in the kinetics of the ligand receptor interaction might be involved. In intact cell binding experiments, the apparent affinity of morphine changes very little, regardless of the length of incubation (Toll, 1995). In the present report, the inhibition curves for the high-affinity agonists DAMGO and etorphine were shifted to the right with shorter incubation periods, probably because of slow association kinetics leading to low apparent affinities. This was particularly evident for etorphine, for which the $\mathrm{IC}_{50}$ value shifts 50 -fold with the shorter incubation period. The latter finding is consistent with the fact that MOR is internalized after stimulation by etorphine (Keith et al., 1998; Whistler et al., 1999). These findings suggest that intracellular signaling, including PKC activation, might occur more rapidly after administration of morphine compared with DAMGO. Thus, the PKC activation after stimulation by morphine, but not DAMGO, likely prohibits MOR internalization through an inhibition of MOR phosphorylation by GRKs. This speculation is supported by the finding that the stability of the MOR activation state required for GRK phosphorylation and $\beta$-arrestin binding induced by DAMGO stimulation is greater than that by morphine stimulation (Zhang et al., 1998).

The next issue to be discussed is the possible site of action of PKC in the modulation of MOR internalization. GRK2 is involved in opioid receptor signaling but is an unlikely mechanism for PKC-induced inhibition of internalization, because the translocation of GRK2 to cell surface membranes is rather enhanced to accelerate receptor internalization by PKC-mediated phosphorylation (Whinster et al., 1996). GRK5 is inactivated by PKC (Kovoor et al., 1998); thus this molecule might be a target for PKC-induced inhibition of internalization. This mechanism is not perfect, however, because it takes $>12 \mathrm{hr}$ after exposure to the $\mu$-agonist for it to occur. Alternatively, MOR might be the target for PKC, because PKC is implicated in the agonist-induced phosphorylation of MOR (Chen and Yu, 1994; Mestek et al., 1995; L. Zhang et al., 1996), although it remains to be determined whether MOR is directly phosphorylated by PKC. The use of mutagenized MOR lacking PKC phosphorylation sites for the study of desensitization and internalization would provide direct evidence.
In conclusion, the present study suggests that $\mathrm{PKC}$ has a key role in the inhibition of MOR internalization and the development of acute tolerance to peripheral morphine analgesia.

\section{REFERENCES}

Afify EA, Law PY, Riedl M, Elde R, Loh HH (1998) Role of carboxyl terminus of $\mu$ - and $\delta$-opioid receptor in agonist-induced downregulation. Mol Brain Res 54:24-34.

Becker TC, Noel RJ, Coats WS, Gomez-Foix AM, Alam T, Gerard RD, Newgard CB (1994) Use of recombinant adenovirus for metabolic engineering of mammalian cells. Methods Cell Biol 43:161-189.

Bunemann M, Hosey MM (1999) G-protein coupled receptor kinases as modulators of G-protein signalling. J Physiol (Lond) 517:5-23.

Burford NT, Tolbert LM, Sadee W (1998) Specific G protein activation and $\mu$-opioid receptor internalization caused by morphine, DAMGO and endomorphin I. Eur J Pharmacol 342:123-126.

Chen Y, Yu L (1994) Differential regulation by cAMP-dependent protein kinase and protein kinase $\mathrm{C}$ of the mu opioid receptor coupling to a $\mathrm{G}$ protein-activated $\mathrm{K}^{+}$channel. J Biol Chem 269:7839-7842.

El Kouhen R, Kouhen OM, Law PY, Loh HH (1999) The absence of a direct correlation between the loss of $\left[\mathrm{D}-\mathrm{Ala}^{2}, \mathrm{MePhe}^{4}, \mathrm{Gly}^{\left.-\mathrm{Ol}^{5}\right]}{ }^{5}\right.$ enkephalin inhibition of adenylyl cyclase activity and agonist-induced mu-opioid receptor phosphorylation. J Biol Chem 274:9207-9215.

Fukuda K, Kato S, Mori K, Nishi M, Takeshima H (1993) Primary structures and expression from cDNAs of rat opioid receptor $\delta$ - and $\mu$-subtypes. FEBS Lett 327:311-314.

Fukushima N, Ueda H, Hayashi C, Katayama T, Miyamae T, Misu Y (1994) Species and age-dependent differences of functional coupling between opioid delta-receptor and G-proteins and possible involvement of protein kinase C in striatal membranes. Neurosci Lett 176:55-58.

Gucker S, Bidlack JM (1992) Protein kinase C activation increases the rate and magnitude of agonist-induced $\delta$-opioid receptor downregulation in NG108-15 cells. Mol Pharmacol 42:656-665.

Harada H, Ueda H, Katada T, Ui M, Satoh M (1990) Phosphorylated $\mu$-opioid receptor purified from rat brains lacks functional coupling with Gi1, a GTP-binding protein in reconstituted lipid vesicles. Neurosci Lett 113:47-49.

Hasbi A, Polastron J, Allouche S, Stanasila L, Massotte D, Jauzac P (1998) Desensitization of the delta-opioid receptor correlates with its phosphorylation in SK-N-BE cells: involvement of a $G$ protein-coupled receptor kinase. J Neurochem 70:2129-2138.

Hayashi C, Ueda H, Fukushima N, Katayama T, Misu Y (1995) Protein kinase C inhibitor potentiates the agonist-induced GTPase activity in COS cell membranes expressing $\delta$-opioid receptor. Mol Brain Res 33:347-350

Hylden JL, Wilcox GL (1980) Intrathecal morphine in mice: a new technique. Eur J Pharmacol 67:313-316.

Iadarola MJ, Lee S, Mannes AJ (1997) Gene transfer approaches to pain control. Molecular Neurobiology of Pain, pp 337-359. Seattle: IASP Press.

Inoue M, Ueda H (2000) Protein kinase C-mediated acute tolerance to peripheral $\mu$-opioid analgesia in the bradykinin-nociception test in mice. J Pharmacol Exp Ther 293:662-669.

Inoue M, Kobayashi M, Kozaki S, Zimmer A, Ueda H (1998a) Nociceptin/orphanin FQ-induced nociceptive responses through substance $\mathrm{P}$ release from peripheral nerve endings in mice. Proc Natl Acad Sci USA 95:10949-10953.

Inoue M, Nakayamada H, Tokuyama S, Ueda H (1998b) In vivo signal transduction of tetrodotoxin-sensitive nociceptive responses by substance $\mathrm{P}$ given into the plantar of mouse hind limb. Cell Mol Neurobiol 18:555-561.

Kao AW, Ceresa BP, Santeler SR, Pessin JE (1998) Expression of a dominant interfering dynamin mutant in 3T3L1 adipocytes inhibits GLUT4 endocytosis without affecting insulin signaling. J Biol Chem 273:25450-25457.

Kase H, Iwahashi K, Nakanishi S, Matsuda Y, Yamada K, Takahashi M, Murakata C, Sato A, Kaneko M (1987) K-252 compounds, novel and potent inhibitors of protein kinase $\mathrm{C}$ and cyclic nucleotide-dependent protein kinases. Biochem Biophys Res Commun 142:436-440.

Kashiwada Y, Huang L, Ballas LM, Jiang JB, Janzen WP, Lee KH (1994) New hexahydroxybiphenyl derivatives as inhibitors of protein kinase C. J Med Chem 37:195-200.

Keith DE, Murray SR, Zaki PA, Chu PC, Lissin DV, Kang L, Evans CJ, von Zastrow M (1996) Morphine activates opioid receptors without causing their rapid internalization. J Biol Chem 271:19021-19024.

Keith DE, Anton B, Murray SR, Zaki PA, Chu PC, Lissin DV, Monteillet-Agius G, Stewart PL, Evans CJ, von Zastrow M (1998) Mu-opioid receptor internalization: opiate drugs have differential effects on a conserved endocytic mechanism in vitro and in the mammalian brain. Mol Pharmacol 53:377-384.

Koch T, Kroslak T, Mayer P, Raulf E, Hollt V (1997) Site mutation in the rat $\mu$-opioid receptor demonstrates the involvement of calcium/ 
calmodulin-dependent protein kinase II in agonist-mediated desensitization. J Neurochem 69:1767-1770.

Kovoor A, Nappey V, Kieffer BL, Chavkin C (1997) Mu and delta opioid receptors are differentially desensitized by the coexpression of beta-adrenergic receptor kinase 2 and beta-arrestin 2 in Xenopus oocytes. J Biol Chem 272:27605-27611.

Kovoor A, Celver JP, Wu A, Chavkin C (1998) Agonist induced homologous desensitization of $\mu$-opioid receptors mediated by $\mathrm{G}$ proteincoupled receptor kinases is dependent on agonist efficacy. Mol Pharmacol 54:704-711.

Kramer HK, Simon EJ (1999) Role of protein kinase C (PKC) in agonist-induced $\mu$-opioid receptor down-regulation: II. Activation and involvement of the $\alpha, \epsilon$, and $\zeta$ isoforms of PKC. J Neurochem 72:594-604.

Krueger KM, Daaka Y, Pitcher JA, Lefkowitz RJ (1997) The role of sequestration in $G$ protein-coupled receptor resensitization. Regulation of $\beta_{2}$-adrenergic receptor dephosphorylation by vesicular acidification. J Biol Chem 272:5-8.

Law PY, Wong YH, Loh HH (2000) Molecular mechanisms and regulation of opioid receptor signaling. Annu Rev Pharmacol Toxicol 40:389-430.

Lu Z, Hornia A, Jiang YW, Zang Q, Ohno S, Foster DA (1997) Tumor promotion by depleting cells of protein kinase $\mathrm{C}$ delta. Mol Cell Biol 17:3418-3428.

McConalogue K, Grady EF, Minnis J, Balestra B, Tonini M, Brecha NC, Bunnett NW, Sternini C (1999) Activation and internalization of the $\mu$-opioid receptor by the newly discovered endogenous agonists, endomorphin-1 and endomorphin-2. Neuroscience 90:1051-1059.

Mestek A, Hurley JH, Bye LS, Campbell AD, Chen Y, Tian M, Liu J, Schulman H, Yu L (1995) The human mu opioid receptor: modulation of functional desensitization by calcium/calmodulin-dependent protein kinase and protein kinase C. J Neurosci 15:2396-2406.

Narita M, Narita M, Mizoguchi H, Tseng LF (1995) Inhibition of protein kinase $\mathrm{C}$, but not of protein kinase $\mathrm{A}$, blocks the development of acute antinociceptive tolerance to an intrathecally administered $\mu$-opioid receptor agonist in the mouse. Eur J Pharmacol 280:R1-R3.

Nestler EJ (1992) Molecular mechanisms of drug addiction. J Neurosci $12: 2439-2450$.

Onogi T, Minami M, Katao Y, Nakagawa T, Aoki Y, Toya T, Katsumata S, Satoh M (1995) DAMGO, a $\mu$-opioid receptor selective agonist, distinguishes between $\mu$ - and $\delta$-opioid receptors around their first extracellular loops. FEBS Lett 357:93-97.

Pak Y, O'Dowd BF, George SR (1997) Agonist-induced desensitization of the $\mu$ opioid receptor is determined by threonine 394 preceded by acidic amino acids in the $\mathrm{COOH}$-terminal tail. J Biol Chem 272:24961-24965.

Pei G, Kieffer BL, Lefkowitz RJ, Freedman NJ (1995) Agonistdependent phosphorylation of the mouse delta-opioid receptor: involvement of $\mathrm{G}$ protein-coupled receptor kinases but not protein kinase C. Mol Pharmacol 48:173-177.

Polakiewicz RD, Schieferl SM, Dorner LF, Kansra V, Comb MJ (1998) A mitogen-activated protein kinase pathway is required for $\mu$-opioid receptor desensitization. J Biol Chem 273:12402-12406.

Schulz S, Schreff M, Koch T, Zimprich A, Gramsch C, Elde R, Hollt V (1998) Immunolocalization of two mu-opioid receptor isoforms
(MOR1 and MOR1B) in the rat central nervous system. Neuroscience 82:613-622.

Smart D, Lambert DG (1996) The stimulatory effects of opioids and their possible role in the development of tolerance. Trends Pharmacol Sci 17:264-269.

Sternini C, Spann M, Anton B, Keith DJ, Bunnett NW, von Zastrow M, Evans C, Brecha NC (1996) Agonist-selective endocytosis of mu opioid receptor by neurons in vivo. Proc Natl Acad Sci USA 93:9241-9246.

Sumi M, Kiuchi K, Ishikawa T, Ishii A, Hagiwara M, Nagatsu T, Hidaka $\mathrm{H}$ (1991) The newly synthesized selective $\mathrm{Ca}^{2+} /$ calmodulin dependent protein kinase II inhibitor KN-93 reduces dopamine contents in PC12h cells. Biochem Biophys Res Commun 181:968-975.

Toll L (1995) Intact cell binding and the relation to opioid activates in SH-SY5Y cells. J Pharmacol Exp Ther 273:721-727.

Ueda H (1999) In vivo molecular signal transduction of peripheral mechanisms of pain. Jpn J Pharmacol 79:263-268.

Ueda H, Miyamae T, Hayashi C, Watanabe S, Fukushima N, Sasaki Y, Iwamura T, Misu Y (1995) Protein kinase C involvement in homologous desensitization of $\delta$ opioid receptor coupled to $\mathrm{G}_{\mathrm{i} 1}$-phospholipase $\mathrm{C}$ activation in Xenopus oocytes. J Neurosci 15:7485-7499.

Way KJ, Chou E, King GL (2000) Identification of PKC-isoformspecific biological actions using pharmacological approaches. Trends Pharmacol Sci 21:181-187.

Wenzel-Seifert K, Schachtele C, Seifert R (1994) N-protein kinase C isoenzymes may be involved in the regulation of various neutrophil functions. Biochem Biophys Res Commun 200:1536-1543.

Whinster R, Freund S, Krasel C, Hoppe E, Lohse MJ (1996) Protein kinase cross-talk: membrane targeting of the $\beta$-adrenergic receptor kinase by protein kinase C. Proc Natl Acad Sci USA 93:2105-2109.

Whistler JL, Chuang HH, Chu P, Jan LY, von Zastrow M (1999) Functional dissociation of $\mu$ opioid receptor signaling and endocytosis: implications for the biology of opiate tolerance and addiction. Neuron 23:737-746.

Xu W, Ozdener F, Li JG, Chen C, Riel JK, Weinstein H, Liu-Chen LY (1999) Functional role of the spatial proximity of Asp114 (2.50) in TMH 2 and Asn332 (7.49) in TMH 7 of the $\mu$ opioid receptor. FEBS Lett 447:318-324.

Zhang J, Ferguson SS, Barak LS, Menard L, Caron MG (1996) Dynamin and $\beta$-arrestin reveal distinct mechanisms for $\mathrm{G}$ protein-coupled receptor internalization. J Biol Chem 271:18302-18305.

Zhang J, Barak LS, Winkler KE, Caron MG, Ferguson SSG (1997) A central role for beta-arrestins and clathrin-coated vesicle-mediated endocytosis in beta 2 -adrenergic receptor resensitization. Differential regulation of receptor resensitization in two distinct cell types. J Biol Chem 272:27005-27014.

Zhang J, Ferguson SSG, Barak LS, Bodduluri SR, Laporte SA, Law PY, Caron MG (1998) Role for $G$ protein-coupled receptor kinase in agonist-specific regulation of $\mu$-opioid receptor responsiveness. Proc Natl Acad Sci USA 95:7157-7162.

Zhang L, Yu Y, Mackin S, Weight FF, Uhl GR, Wang JB (1996) Differential $\mu$ opioid receptor phosphorylation and desensitization induced by agonists and phorbol esters. J Biol Chem 271:11449-11454.

Zimmermann M (1983) Ethical guidelines for investigations of experimental pain in conscious animals. Pain 16:109-110. 